5 - ORIGINAL ARTICLE ISCHEMIA-REPERFUSION

\title{
Mechanisms of the beneficial effect of sevoflurane in liver ischemia/reperfusion injury ${ }^{1}$
}

\author{
Fernanda Paula Cavalcante, Ana Maria Mendonça Coelho" ${ }^{\mathrm{II}}$, Marcel Cerqueira Cesar Machado ${ }^{\mathrm{III}}$, Sandra Nassa Sampietre ${ }^{\mathrm{IV}}$, \\ Rosely Antunes Patzinav, Márcio Augusto Diniz ${ }^{\text {VI }}$, Eleazar Chaib ${ }^{\text {VII }}$, Luiz Augusto Carneiro D'Albuquerque ${ }^{\text {VII }}$
}

DOI: http://dx.doi.org/10.1590/S0102-865020150110000005

IFellow PhD degree, Postgraduate Program in Gastroenterology, School of Medicine, Universidade de São Paulo (USP), Brazil. Surgical procedures, acquisition of data, manuscript writing.

IIPhD, Division of Liver Transplantation, Department of Gastroenterology, Medical Investigation Laboratory (LIM/37), School of Medicine, USP, Sao Paulo-SP, Brazil. Biochemical analysis, manuscript writing.

IIIPhD, Division of Liver Transplantation, Department of Gastroenterology, Medical Investigation Laboratory (LIM/37), School of Medicine, USP, Sao Paulo-SP, Brazil. Conception, analysis and interpretation of data; manuscript writing.

${ }^{\mathrm{IV}}$ TSc, Division of Liver Transplantation, Department of Gastroenterology, Medical Investigation Laboratory (LIM/37), School of Medicine, USP, Sao Paulo-SP, Brazil. Technical procedures.

${ }^{\mathrm{v}} \mathrm{PhD}$, Department of Pathology, School of Medicine, USP, Sao Paulo-SP, Brazil. Histological analysis.

${ }^{V} \mathrm{PhD}$, Department of Gastroenterology, School of Medicine, USP, Sao Paulo-SP, Brazil. Statistical analysis.

VIIPhD, Division of Liver Transplantation, Department of Gastroenterology, Medical Investigation Laboratory (LIM/37), School of Medicine, USP, Sao Paulo-SP, Brazil. Critical revision.

\section{ABSTRACT}

PURPOSE: To evaluate the underlying mechanisms by which sevoflurane protects the liver against ischemia/reperfusion injury evaluate the mechanism by which sevoflurane exerts this protective effect.

METHODS: Twenty-six rats were subjected to partial ischemia/reperfusion injury for 1h: one group received no treatment, one group received sevoflurane, and sham group of animals received laparotomy only. Four hours after reperfusion, levels of alanine and aspartate aminotransferases, tumor necrosis factor- $\alpha$, and interleukins 6 and 10 were measured. Analyses of mitochondrial oxidation and phosphorylation, malondialdehyde content, histology, and pulmonary vascular permeability were performed.

RESULTS: Serum levels of alanine and aspartate aminotransferases were significantly lower in the sevoflurane group compared to untreated controls $(\mathrm{p}<0.05)$. The sevoflurane group also showed preservation of liver mitochondrial function compared to untreated controls $(p<0.05)$. Sevoflurane administration did not alter increases in serum levels of tumor necrosis factor- $\alpha$, and interleukins 6 and 10. Sevoflurane treatment significantly reduced the coagulative necrosis induced by ischemia/reperfusion $(\mathrm{p}<0.05)$. Pulmonary vascular permeability was preserved in the sevoflurane group compared to untreated controls.

CONCLUSION: Sevoflurane administration protects the liver against ischemia/reperfusion injury, via preservation of mitochondrial function, and also preserves lung vascular permeability.

Key words: Ischemia. Reperfusion. Liver. Lung. Cytokines. Rats. 


\section{Introduction}

The reperfusion of tissue after a prolonged ischemia results in ischemia/reperfusion (I/R) injury, which can ultimately lead to multiple organ dysfunction in cases where a severe systemic inflammatory response occurs ${ }^{1-3}$. Ischemia of the liver, which can occur with hepatectomy, transplantation, trauma, or shock, deprives the organ of oxygen, leading to mitochondrial dysfunction and energy deficiency ${ }^{4}$. Swelling of hepatocytes and endothelial cells after reperfusion contributes to narrowing of sinusoidal blood vessels and platelet aggregation, thus occluding hepatic microcirculation. The subsequent inflammatory response produces reactive oxygen species and cytokines, causing further cell damage .

The liver can be protected from I/R injury to some extent with sevoflurane administration ${ }^{6-9}$. It is thought that sevoflurane attenuates the inflammation, as some volatile anesthetics have anti-inflammatory properties ${ }^{10,11}$. However, hepatic ATP levels have also been shown to decrease following $I / R$ injury ${ }^{4,12}$. Thus, sevoflurane may also protect mitochondrial function by acting on ATP-dependent potassium channels ${ }^{13,14}$. The aim of the present study was to identify the underlying mechanisms by which sevoflurane protects the liver against I/R injury.

\section{Methods}

The experimental protocol was approved by the Ethics Committee for Animal Research from School of Medicine, Universidade de São Paulo (approval code 147/2012). Animals received care in accordance with the Guide for the Care and Use of Laboratory Animals.

Male Wistar rats weighing 230-280g were individually housed and kept under standard conditions (12-h light/dark cycle at $22-28^{\circ} \mathrm{C}$ ) with free access to a standard rat chow and water.

\section{Experimental design and study protocol}

Animals were anesthetized with an i.p. injection of ketamine (30 mg/kg Ketalar; Cristalia, SP, Brazil) and xylazine (30 mg/kg Rompum; Bayer AG, Leverkusen, Germany) and subjected to orotracheal intubation and mechanical ventilation (Small Animal Ventilator model 683; Harvard Apparatus, Holliston, MA, United States). Body temperature was monitored throughout the procedure and maintained at $35-37^{\circ} \mathrm{C}$. An upper median abdominal laparotomy was performed, and the pedicle to the left lateral and median hepatic lobes was dissected and occluded for $1 \mathrm{~h}$ with a nontraumatic microvascular clamp. The abdominal incision was closed, followed by a reperfusion period of $4 \mathrm{~h}$. This model of partial hepatic ischemia induces ischemia in $\sim 70 \%$ of the liver parenchyma without intestinal congestion ${ }^{15}$.

A total of 39 rats were divided into three groups: sham $(n=13)$, with rats receiving a median laparotomy and liver manipulation without liver ischemia; no treatment I/R (NT) $(n=$ $13)$; and sevoflurane treated I/R (Sevo) $(n=13)$. In sham and notreatment groups, ketamine $(15 \mathrm{mg} / \mathrm{kg}$, i.p.) was administered as needed during the I/R period. In the sevoflurane group, sevoflurane (Abbot Laboratories, Chicago, IL, United States) was administered continuously via orotracheal tube through a calibrated vaporizer at a concentration of $2 \%$ expired fraction (1 MAC).

After the 4-h reperfusion, blood samples were collected via cardiac puncture, and animals were euthanized by crosssection of the abdominal aorta. Liver tissue was collected from ischemic segments for biochemical and histologic examinations. Pulmonary tissue was collected for vascular permeability analysis.

\section{Serum aspartate aminotransferase (AST) and ala- nine aminotransferase (ALT) levels}

Serum AST and ALT levels were assayed using the optimized ultraviolet method (COBRAS MIRA; Roche Diagnostics, Basel, Switzerland). Results are expressed as U/L.

\section{Oxidation and phosphorylation of liver mitochon- dria}

Liver mitochondria were prepared as described previously ${ }^{16}$. Briefly, mitochondrial oxygen consumption was measured polarographically using an oxygraph (Gilson 5/6H; Gilson Inc., Middleton, WI, United States) in a closed reaction vessel fitted with a Clark oxygen electrode (YSI Inc., Yellow Springs, $\mathrm{OH}$, United States) at $28^{\circ} \mathrm{C}$. Mitochondrial activated (S3) and basal (S4) states were measured as the rate of oxygen consumption in the presence or absence, respectively, of ADP. S3 and $\mathrm{S} 4$ are reported as nmol oxygen per mg mitochondrial protein per min. The respiratory control ratio (RCR) was calculated as S3/ $\mathrm{S} 4$ and the ADP/oxygen (ADP/O) ratio was calculated as moles of 
ATP formed from ADP per atom of oxygen consumed as indices of mitochondrial oxidation and phosphorylation activities ${ }^{17}$. Mitochondrial protein content was determined by the method of Lowry et al. ${ }^{18}$.

\section{Lipid peroxidation analysis}

Malondialdehyde (MDA) content was evaluated as a measure of lipid peroxidation. Ischemic liver tissues $(100 \mathrm{mg} /$ $\mathrm{mL}$ ) were homogenized in $1.15 \% \mathrm{KCl}$ buffer and centrifuged at $14,000 \times g$ for $20 \mathrm{~min}$. The supernatant was then added to a reaction mixture consisting of $1.5 \mathrm{~mL} 0.8 \%$ thiobarbituric acid, $200 \mu \mathrm{L} \mathrm{8.1 \%} \mathrm{(v/v)} \mathrm{sodium} \mathrm{dodecyl} \mathrm{sulfate,} 1.5 \mathrm{~mL} \mathrm{20 \%}$ acetic acid ( $\mathrm{pH} 3.5$ ), and $600 \mu \mathrm{L}$ distilled water and heated to $90^{\circ} \mathrm{C}$ for 45 min. After cooling to room temperature, the samples were cleared by centrifugation $(10,000 \times g$ for $10 \mathrm{~min})$, and the absorbance was measured at $532 \mathrm{~nm}$ using malondialdehyde bis (dimethyl acetal) as an external standard. The content of lipid peroxides is expressed as nmol MDA per mg of protein ${ }^{19}$.

\section{Histologic analysis}

Ischemic liver samples were fixed in $10 \%$ buffered formalin for standard hematoxylin and eosin staining. The same pathologist performed the histologic evaluations in a blinded manner. The severity of injury was scored according to the incidence of coagulative necrosis on a scale of 0 to 9: $0=$ no necrosis, $3=$ mild, $6=$ moderate, $9=$ severe $(\text { Table } 1)^{20}$.

TABLE 1 - Graduation of coagulative necrosis score.

\begin{tabular}{cc}
\hline Coagulative Necrosis & Score \\
\hline No necrosis & 0 \\
Mild & $3(1 \times 3)$ \\
Moderate & $6(2 \times 3)$ \\
Severe & $9(3 \times 3)$ \\
\hline
\end{tabular}

\section{Determination of inflammatory mediators}

Serum levels of tumor necrosis factor- $\alpha$, interleukin- 6 , and interleukin-10 were determined by ELISA using commercially available kits (Invitrogen of Thermo Fisher Scientific, Waltham, MA, United States).

\section{Lung tissue microvascular permeability analysis}

Increases in lung microvascular permeability were quantified by the Evans blue dye (EBD) extravasation technique as described previously ${ }^{21}$. EBD (20 mg/kg of body weight) was injected via the dorsal penile vein $15 \mathrm{~min}$ before euthanasia. After blood sample collection, the lungs were perfused with $30-50 \mathrm{~mL}$ of $0.9 \% \mathrm{NaCl}$ at $10 \mathrm{~mL} / \mathrm{min}$ using a syringe pump (model 975; Harvard Apparatus) and weighed. One small fragment was dried at $60^{\circ} \mathrm{C}$ for calculation of total dry weight. To extract the dye, the lung was incubated with formamide ( $4 \mathrm{~mL} / \mathrm{mg}$ of tissue) for $24 \mathrm{~h}$ at room temperature, and the absorbance of the solution at $620 \mathrm{~nm}$ was measured on a microplate reader (ELX 808; Bio-Tek Instruments, Winooski, VT, United States). The results are expressed as $\mu \mathrm{g}$ of EBD per $g$ of dry weight tissue to avoid undervaluation due to edema formation ${ }^{22}$.

\section{Statistical analysis}

The data are expressed as mean $\pm \mathrm{SD}$ or as median (interquartile range). Multiple group comparisons were assessed with analyses of variance or Kruskal-Wallis, followed by Tukey's tests. The R program version 2.15.2 (The R Foundation for Statistical Computing) was used for statistical analysis, and $\mathrm{p}<0.05$ was considered statistically significant.

\section{Results}

\section{Serum AST and ALT levels}

Liver I/R resulted in significant increases in serum AST and ALT levels in no-treatment and sevoflurane groups compared to the sham group $(\mathrm{p}<0.05)$ (Figure 1). Treatment with sevoflurane significantly reduced AST and ALT levels compared to the notreatment group $(\mathrm{p}<0.05)$. 

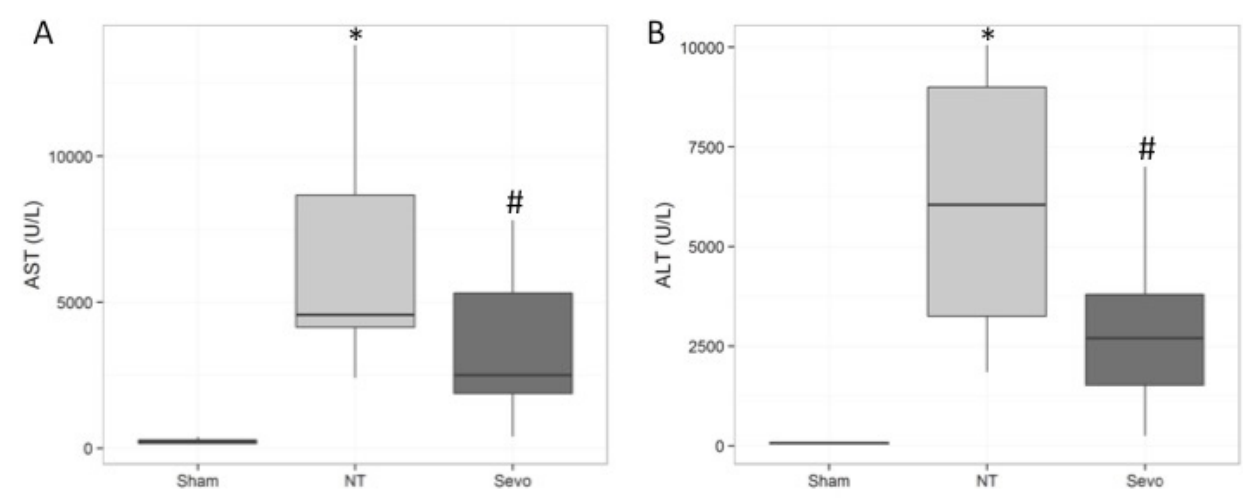

FIGURE 1 - Effects of sevoflurane on serum activities: (A) aspartate aminotransferase (AST) and (B) alanine aminotransferase (ALT) in liver/ ischemia reperfusion (I/R). Sham group consisted of animals submitted to liver manipulation. Groups of animals submitted to liver I/R: No Treatment (NT): animals without sevoflurane administration during I/R injury time, and Sevoflurane group (Sevo): sevoflurane was administered during the whole I/R injury time. Data are expressed as median (quartile $25 \%$ - quartile $75 \%$ ) $\quad *{ }^{*} p<0.05$

\section{Oxidation and phosphorylation of liver mitochon-} dria

After $\mathrm{I} / \mathrm{R}, \mathrm{S} 3$ and $\mathrm{ADP} / \mathrm{O}$ values were significantly lower in the no-treatment group compared to sham and sevoflurane groups $(\mathrm{p}<0.05)$ (Figure 2). However, there was no difference in
S3 values between the sham and sevoflurane groups. Compared to the sham group, RCR ratios were significantly decreased in the no-treatment and sevoflurane groups $(\mathrm{p}<0.05)$, however the sevoflurane group showed a significant increase when compared to the no-treatment group $(\mathrm{p}<0.05)$. No differences in S4 levels were found among the three groups.
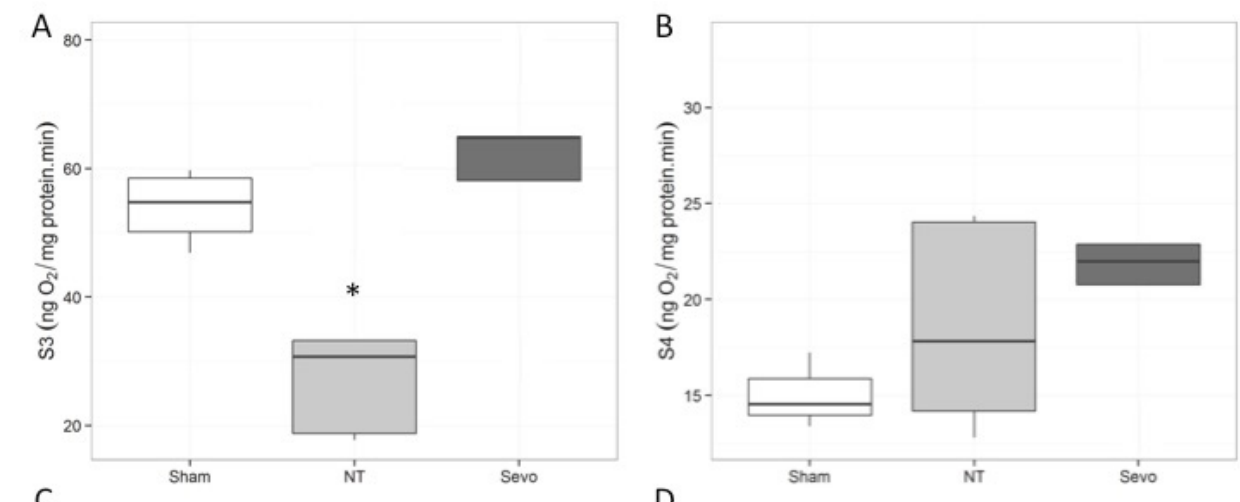

$$
\text { C }
$$
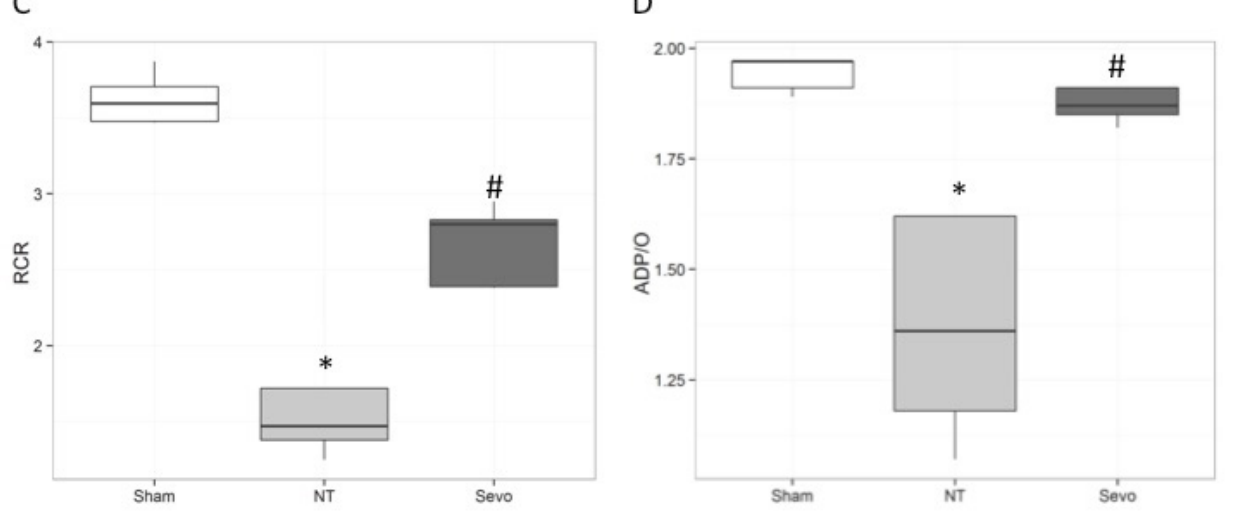

FIGURE 2 - Effects of sevoflurane on liver mitochondrial oxidation and phosphorylation activities in liver/ischemia reperfusion (I/R). (A): State 3 respiration (S3), (B): State 4 respiration (S4), (C): Respiratory control rate (RCR), and (D): ADP/O ratio. Sham group consisted of animals submitted to liver manipulation. Groups of animals submitted to I/R: No Treatment (NT): animals without sevoflurane administration during I/R injury time, and Sevoflurane group (Sevo): sevoflurane was administered during the whole I/R injury time. Data are expressed as median (quartile $25 \%$ quartile $75 \%$ ) *, ${ }^{*} \mathrm{p}<0.05$ 


\section{Liver MDA content}

There were no differences in ischemic liver MDA content among groups (data not shown).

\section{Liver histology}

$\mathrm{I} / \mathrm{R}$ induced necrosis in liver samples, observed as a significant increase in the coagulative necrosis score in the no-treatment and sevoflurane groups compared to the sham group ( $\mathrm{p}<0.05$ ) (Figure 3). However, sevoflurane administration significantly reduced the severity of necrosis when compared to the untreated group $(\mathrm{p}<0.05)$.

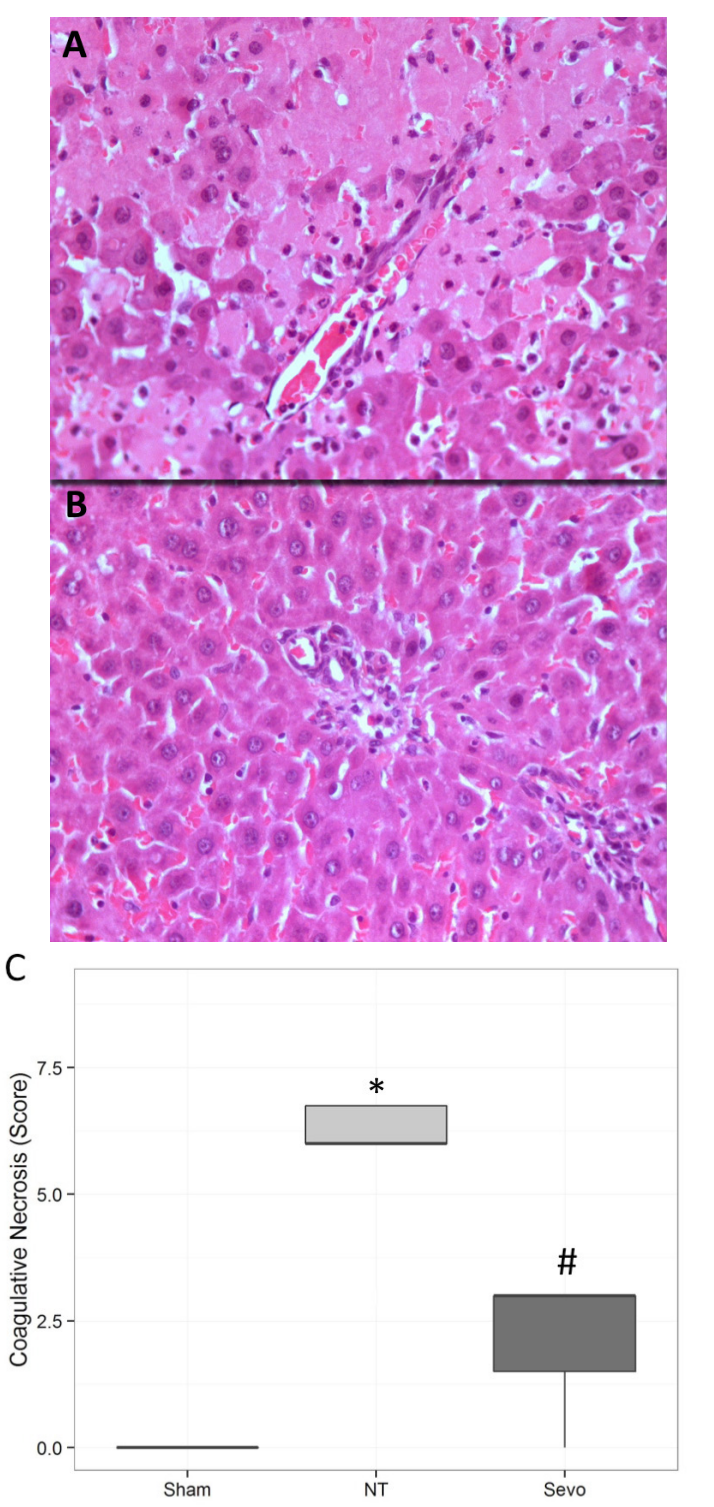

FIGURE 3 - Liver coagulative necrosis. (A) No-treatment group and (B) Sevoflurane group (hematoxylin and eosin; x400). (C) Quantification of necrosis. NT, no-treatment; Sevo, sevoflurane treated. Data are expressed as median (interquartile range); ${ }^{*} \mathrm{p}<0.05$ vs sham; $\# \mathrm{p}<0.05$ vs NT.

\section{Serum levels of inflammatory mediators}

$\mathrm{I} / \mathrm{R}$ resulted in a significant increase in serum levels of tumor necrosis factor- $\alpha$, interluekin- 6 , and interleukin-10 in the no-treatment and sevoflurane groups compared to the sham group $(p<0.05)$ (Table 2). However, levels were not different between the sevoflurane and no-treatment groups.

TABLE 2 - Serum levels of TNF- $\alpha$, IL-6, and IL-10.

\begin{tabular}{cccc}
\hline & TNF- $\alpha(\mathrm{pg} / \mathrm{ml})$ & IL-6 $(\mathrm{pg} / \mathrm{ml})$ & IL-10 $(\mathrm{pg} / \mathrm{ml})$ \\
\hline Sham & $3 \pm 5^{*}$ & $16 \pm 27^{*}$ & $18 \pm 19^{*}$ \\
No Treatment & $105 \pm 62$ & $684 \pm 264$ & $240 \pm 105$ \\
Sevoflurane & $66 \pm 47$ & $779 \pm 421$ & $296 \pm 48$ \\
\hline Data are presented as mean \pm SEM &
\end{tabular}

Data are presented as mean \pm SEM

${ }^{*} \mathrm{p}<0.05$ vs any group

\section{Lung microvascular permeability}

I/R significantly increased lung microvascular permeability as assessed by EBD extravasation $(\mathrm{p}<0.05)$ (Figure 4). Sevoflurane treatment completely abrogated this, with no difference between the sham and sevoflurane groups.

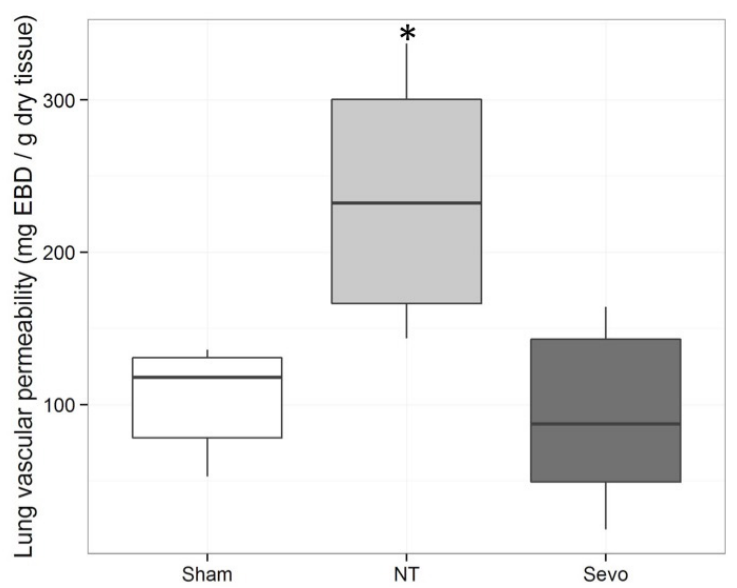

FIGURE 4 - Effects of sevoflurane on lung permeability analysis evaluated through Evans blue dye (EBD) extravasation in liver/ischemia reperfusion (I/R). Sham group consisted of animals submitted to liver manipulation. Groups of animals submitted to liver I/R: No Treatment (NT): animals without sevoflurane administration during I/R injury time, and Sevoflurane group (Sevo): sevoflurane was administered during the whole I/R injury time. Data are expressed as median (quartile $25 \%$ quartile $75 \%$ ) $* \mathrm{p}<0.05$

\section{Discussion}

Hepatic I/R injury alters liver mitochondrial function, resulting in degeneration and necrosis in the liver that is 
characteristic of cellular ischemia. The findings presented in this study show that sevoflurane restores mitochondrial function as a mechanism to protect the liver against $\mathrm{I} / \mathrm{R}$ injury. This was observed as preserved S3 state respiration, RCR, and ADP/O ratios, as well as by reduced coagulative necrosis as assessed by histology. The preservation of mitochondrial function by sevoflurane resulted in reduced hepatic parenchymal damage and lower transaminase levels. It is possible that sevoflurane activated mitoK $_{\text {ATP }}$ channels $^{22-27}$ and therefore decreased the intracellular calcium concentration, thus reducing mitochondrial damage in hepatic I/R injury.

Although previous studies have indicated that sevoflurane suppresses the production of reactive oxygen species and reduces lipid peroxidation in liver parenchyma $a^{6,7}$, the results presented here failed to show significant differences in liver MDA content among the groups. Additionally, sevoflurane did not significantly reduce serum levels of inflammatory factors, which is consistent with previous studies ${ }^{6,7}$. This suggests that the protection afforded by sevoflurane administration is independent of the release of proinflammatory cytokines from activated Kupffer cells in I/R injury ${ }^{28,29}$.

Analyses of EBD extravasation revealed that sevoflurane preserves lung microvascular permeability. As no reduction in inflammatory mediators was observed, we speculate that sevoflurane has a local beneficial effect in the lungs. This hypothesis is supported by recent evidence showing a protective effect of sevoflurane during lung ventilation thoracic surgery ${ }^{28}$ and reduction of lung I/R injury ${ }^{29}$.

\section{Conclusion}

The mechanism by which this occurs cannot be fully addressed by this study alone, but it probably involves preservation of mitochondrial function and protection of lung parenchyma, without a reduction of the systemic inflammatory response.

\section{References}

1. Serracino-Inglott F, Habib NA, Mathie RT. Hepatic ischemia-reperfusion injury. Am J Surg. 2001;181(2):160-6. PMID: 11425059.

2. Montalvo-Jave EE, Escalante-Tattersfield T, Ortega-Salgado JA, Piña E, Geller DA. Factors in the pathophysiology of the liver ischemia-reperfusion injury. J Surg Res. 2008;147(1):153-9. PMID: 17707862 .

3. Abu-Amara M, Yang SY, Tapuria N, Fuller B, Davidson B, Seifalian A. Liver ischemia/reperfusion injury: Processes in inflammatory networks - a review. Liver Transpl. 2010;16(9):1016-32. doi: 10.1002/lt.22117.

4. Jassem W, Fuggle SV, Rela M, Koo DD, Heaton ND. The role of mitochondria in ischemia/reperfusion injury. Transplantation. 2002;73(4):493-9. PMID: 11889418.

5. Walsh KB, Toledo AH, Rivera-Chavez FA, Lopez-Neblina F, ToledoPereyra LH. Inflammatory mediators of liver ischemia-reperfusion injury. Exp Clin Transplant. 2009;7(2):78-93. PMID: 19715511.

6. Bedirli N, Ofluoglu E, Kerem M, Utebey G, Alper M, Yilmazer D, Bedirli A, Ozlu O, Pasaoglu H. Hepatic energy metabolism and the differential protective effects of sevoflurane and isoflurane anesthesia in a rat hepatic ischemia-reperfusion injury model. Anesth Analg. 2008;106(3):830-7. doi: 10.1213/ane.0b013e3181616fc9.

7. Zhou SP, Jiang P, Liu L, Liu H. Protective effect of sevoflurane on hepatic ischemia/reperfusion injury in the rat: a dose-response study. Eur J Anaesthesiol. 2013;30(10):612-7. doi: 10.1097/ EJA.0b013e3283614023.

8. Soubhia AF, Lauz S, Montero EF, Menezes A, Mespaque LB, Facin E. Effects of the inhalational anesthetics halothane and sevoflurane on an experimental model of hepatic injury. Rev Bras Anestesiol. 2011;61(5):591-603. doi: 10.1016/S0034-7094(11)70070-8.

9. Dal Molin SZ, Kruel CR, de Fraga RS, Alboim C, de Oliveira JR, Alvaresda-Silva MR. Differential protective effects of anaesthesia with sevoflurane or isoflurane: an animal experimental model simulating liver transplantation. Eur J Anaesthesiol. 2014;31(12):695-700. doi: 10.1097/EJA.0000000000000127.

10. Allaouchiche B, Debon R, Goudable J, Chassard D, Duflo F. Oxidative stress status during exposure to propofol, sevoflurane and desflurane. Anesth Analg. 2001;93(4):981-5. PMID: 11574369.

11. Wang H, Lu S, Yu Q, Liang W, Gao H, Li P, Gan Y, Chen J, Gao Y. Sevoflurane preconditioning confers neuroprotection via antiinflammatory effects. Front Biosci (Elite Ed). 2011;3:604-15. PMID: 21196338.

12. Kurokawa T, Kobayashi H, Nonami T, Harada A, Nakao A, Takagi $\mathrm{H}$. Mitochondrial glutathione redox and energy producing function during liver ischemia and reperfusion. J Surg Res. 1996;66(1):1-5. PMID: 8954823.

13. Obal D, Dettwiler S, Favoccia C, Scharbatke H, Preckel B, Schlack W. The influence of mitochondrial KATP-channels in the cardioprotection of preconditioning and postconditioning by sevoflurane in the rat in vivo. Anesth Analg. 2005;101(5):1252-60. PMID: 16243977.

14. Wang JK, Wu HF, Zhou H, Yang B, Liu XZ. Postconditioning with sevoflurane protects against focal cerebral ischemia and reperfusion injury involving mitochondrial ATP-dependent potassium channel and mitochondrial permeability transition pore. Neurol Res. 2015;37(1):77-83. doi: 10.1179/1743132814Y.0000000410.

15. Figueira ER, Bacchella T, Coelho AM, Sampietre, SN Leitão RM, Machado MC. Timing-dependent protection of hypertonic saline solution administration in experimental liver ischemia/ reperfusion injury. Surgery. 2010;147(3):415-23. doi: 10.1016/j. surg.2009.10.018.

16. Coelho AM, Machado MC, Sampietre SN, Leite KR, Oliveira VL, Pinotti HW. Hepatic damage during acute pancreatitis in the rat. Braz J Med Biol Res. 1997;30(8):947-53. PMID: 9361723.

17. Chance B, Williams GR. A simple and rapid assay of oxidative phosphorylation. Nature. 1955;175(4469):1120-1. PMID: 14394122.

18. Lowry OH, Rosebrough NJ, Farr AL, Randall RJ. Protein measurement with the Folin phenol reagent. J Biol Chem. 1951;193(1):265-75. PMID: 14907713.

19. Soriano FG, Liaudet L, Szabó E, Virág L, Mabley JG, Pacher P, Szabó C. Resistance to acute septic peritonitis in poly (ADP-ribose) polymerase-1-deficient mice. Shock. 2002;17(4):286-92. PMID: 11954828.

20. Quireze C, Montero EF, Leitao RM, Juliano Y, Fagundes DJ, Poli- 
de-Figueredo FL. Ischemic preconditioning prevents apoptotic cell death and necrosis in early and intermediate phases of liver ischemia-reperfusion injury in rats. J Invest Surg. 2006;19(4):22936. PMID: 16835137

21. Jancar S, De Giaccobi G, Mariano M, Mencia-Huerta JM, Sirois $\mathrm{P}$, Braquet P. Immune complex induced pancreatitis: effect of BN 52021, a selective antagonist of platelet-activating factor. Prostaglandins. 1988;35(5):757-70. PMID: 2969600.

22. Facundo HT, Fornazari M, Kowaltowski AJ. Tissue protection mediated by mitochondrial $\mathrm{K}+$ channels. Biochim Biophys Acta. 2006;1762(2):202-12. PMID: 16026967.

23. Kohro S, Hogan QH, Nakae Y, Yamakage M, Bosnjak ZJ. Anesthetic effects on mitochondrial ATP-sensitive $\mathrm{K}$ channel. Anesthesiology. 2001;95(6):1435-40. PMID: 11748403.

24. Adamczyk S, Robin E, Simerabet M, Kipnis E, Tavernier B, Vallet B, Bordet R, Lebuffe G. Sevoflurane pre- and post-conditioning protect the brain via the mitochondrial K ATP channel. Br J Anaesth. 2010;104(2):191-200. doi: 10.1093/bja/aep365.

25. Nogueira MA, Coelho AM, Sampietre SN, Patzina RA, D'Albuquerque LA, Machado MC. Beneficial effects of adenosine triphosphatesensitive $\mathrm{K}+$ channel opener on liver ischemia/reperfusion injury. World J Gastroenterol. 2014;20(41):15319-26. doi: 10.3748/wjg. v20.i41.15319.

26. Wanner GA, Ertel W, Müller P, Höfer Y, Leiderer R, Menger MD, Messmer K. Liver ischemia and reperfusion induces a systemic inflammatory response through Kupffer cell activation. Shock. 1996;5(1):34-40. PMID: 8821101

27. Huang HF, Zeng Z, Chen MQ. Roles of Kupffer cells in liver transplantation. Hepatogastroenterology. 2012;59(116):1251-7. doi: 10.5754/hge12046.

28. Erturk E, Topaloglu S, Dohman D, Kutanis D, Beşir A, Demirci Y, Kayir S, Mentese A. The comparison of the effects of sevoflurane inhalation anesthesia and intravenous propofol anesthesia on oxidative stress in one lung ventilation. Biomed Res Int. 2014;2014:360936. doi: 10.1155/2014/360936.
29. Li XH, Liu ZH, Ma HB, Li Y, Zhao H, Che JB, Liu WC, Shi GN. Effect of sevoflurane on tissue permeability of lung ischemia-reperfusion injury in rats. Asian Pac J Trop Med. 2014;7(4):276-9. doi: 10.1016/ S1995-7645(14)60037-7.

\section{Acknowledgement}

To Nilza Molan for expert technical assistance.

\section{Correspondence:}

Prof. Dr. Marcel Cerqueira Cesar Machado

Rua Peixoto Gomide, 515/134

12221-300 São Paulo - SP Brasil

Tel.: (55 11)3251-4135

mccm37@uol.com.br

Received: July 16, 2015

Review: Sep 18, 2015

Accepted: Oct 19, 2015

Conflict of interest: none

Financial source: none

${ }^{1}$ Research performed at Laboratory Abdominal Organ Transplantation (LIM/37), Division of Liver Transplantation, Department of Gastroenterology, School of Medicine, Universidade de São Paulo (USP), Brazil. Part of PhD degree thesis, Postgraduate Program in Gastroenterology. Tutor: Eleazar Chaib. 